\title{
Hércules 56: uma análise do cinema documental e reflexões sobre a teoria social da memória coletiva
}

\author{
Veridiana Domingos Cordeiro*
}

\begin{abstract}
Resumo: 0 artigo apresenta uma análise sociológica do documentário Hércules 56, que retrata o episódio do sequestro do embaixador americano Charles Elbrick, durante a ditadura militar brasileira, com base no relato de alguns envolvidos na ação. 0 texto, em um primeiro momento, se atenta à análise da unidade fílmica e suas construções de sentidos, para, em um segundo momento, lançar uma discussão, tendo como referência a memória dos entrevistados no documentário, sobre a teoria social da memória coletiva de Maurice Halbwachs.
\end{abstract}

Palavras-chave: sociologia do cinema, ditadura militar, memória coletiva.

\section{Introdução}

0 presente texto tem o intuito de analisar o documentário Hércules 56, dirigido por Silvio Da-Rin em 2006, lançando mão de recursos propostos pela própria análise sociológica. Pierre Sorlin (1985) afirma que o impacto produzido pela criação e difusão da televisão, que introduziu as imagens no espaço doméstico, fez com que os cientistas sociais não mais pudessem ignorar o mundo da câmera. É nesse espaço que a sociologia pode inserir-se para contribuir com a percepção dos vários fatores que estão envolvidos em todo o processo da produção fílmica, isto é, ela atenta para o universo onde se relacionam criador, obra, receptor, estrutura social e jogo de interesses. "Nossa percepção é um ato social; se fixa; se organiza em função do que é útil e lícito ver no meio em que vivemos e temos que nos situar" (SoRLIN, 1985, p. 169; tradução nossa).

Contudo, como bem lembra Sorlin, nossa unidade analítica fundamental é a obra fílmica em si, com uma série de sentidos inerentes a ela mesma, tornando-a passível de interpretações diversas. Assim, o presente estudo se retém, principalmente, às indicações e sentidos que se apresentam na tela, nas suas imagens, e na produção de uma expressão ideológica através da qual o "diretor" ${ }^{1}$ se

\footnotetext{
* Graduanda em Ciências Sociais - USP.

${ }^{1}$ Usaremos aqui a palavras "diretor" quando nos referirmos ao "autor" da obra, na acepção de Foucault (2001). "[...] o nome de um autor seria radicalmente diferente de um nome próprio, de um nome comum. Pensar em um nome como sendo um autor, seria pensá-lo como executando um papel, como cumprindo uma função classificatória [...]" (MENEZES, 2007, p. 84). Ou ainda, devemos
} 
situa e define seus objetivos (idem). Ao final, tentaremos, também, estabelecer algumas pinceladas de possíveis diálogos com os efeitos e as consequências que a obra a ser analisada pode engendrar na sociedade, ou seja, de que maneira os “espectadores vão reavaliar sua própria posição" (idem, p. 170) no mundo, com base na obra fílmica apresentada.

Em linhas gerias, o documentário de Silvio Da-Rin se propõe a recontar a história da operação organizada por militantes de três grupos revolucionários de esquerda, a saber: a Aliança Nacional Libertadora (ANL), o Movimento Revolucionário 8 de outubro (MR-8) e a Dissidência da Guanabara (DI-GB). A operação envolvia, grosso modo, o sequestro, na semana da independência de 1969, no Rio de Janeiro, do embaixador americano em troca da liberdade de 15 presos políticos, além da leitura, em rede nacional, de um manifesto escrito por tais grupos. Não apenas a operação, mas, também, a viagem desses presos ao México, é toda reconstruída com base nos depoimentos dos envolvidos.

\section{0 filme como uma construção}

Conclui Merleau-Ponty (2008), apoiado também pelos experimentos feitos por Kuleshov, que a construção de sentido apreendida pelo espectador, de qualquer imagem em um filme nunca é dada por ela mesma, mas sim, é a reunião da imagens dadas do momento atual conjuntamente com as imagens imediatamente anteriores e posteriores, formando assim um todo que se constitui de partes independentes entre $\mathrm{si}^{2}$. Além disso, a construção de sentido do filme também está vinculada à montagem, pois é ela a responsável pela estruturação dos sentidos que vão sendo construídos com a justaposição dos planos, tornando-os, assim, compreensíveis como um todo. É nesse sentido que Bazin (1991) afirma que as imagens não têm sentido único em si mesmas, mas sim, um caráter ambíguo, de modo que isso constitui um dos atributos principais do cinema. Em suma, o filme não é a cópia fiel da realidade e sim uma construção feita pelos seus realizadores.

pensá-lo, como já foi dito, "como uma produção ideológica” (FouCAULT, 2001).

2 A gênese dessa concepção, presente nos escritos de Merleau-Ponty, refere-se diretamente à formulação feita pelo pai da fenomenologia, Edmund Husserl, que formula a ideia de "Presente vivo". 0 presente vivo é, a saber, um presente alargado, um todo formado por impressões do presente, retenções do passado e pretensões do futuro, sendo essas partes independentes entre si (HUSSERL, 2006). 
Embora compartilhe também a ideia conclusiva exposta acima, Dziga Vertov (1983) só admitia no cinema documentário a capacidade de expressar a realidade: a montagem se utilizava, afinal, das imagens captadas pela câmera sobre uma dada realidade. Dessa forma, sendo o filme documentário uma construção, há entre ele e a realidade a câmera:

[...] defendemos a utilização da câmera como cine-olho, muito mais aperfeiçoada do que o olho humano para explorar o caos dos fenômenos visuais que preenchem o espaço, o cine-olho se move no tempo e no espaço, ao mesmo tempo em que colhe e fixa impressões de modo totalmente diverso daquele do olho humano (idem, p. 232).

O cine-olho é capaz de contestar a "representação visual do mundo dada pelo olho humano", propondo um próprio "eu vejo" (idem, p. 255) e criando uma nova percepção do mundo, uma percepção de um modo diferente do que é conhecido pelos espectadores. É também nessa direção que Menezes propõe o filme como uma representificação ${ }^{3}$ do real, pois ele "não xeroca um mundo pretensamente externo sem mediações" (MENEZES, 2003, p. 94). Segundo ele, o produto fílmico é uma "invenção", que envolve atos de "modelar, formar, criar" e por isso "não se confunde com o próprio real" (idem, ibidem).

Aqui, vale lembrar a distinção que Bazin (1991) faz entre aqueles cineastas que acreditam na "imagem" e aqueles que acreditam na "realidade". Os que acreditam na imagem se valem de recursos técnicos (montagem) e recursos cênicos (maquiagem, luz etc.) para estruturar sua obra, sendo o próprio Eisenstein um dos expoentes dessa vertente. E aqueles que acreditam na realidade se valem pouco - na medida em que constroem uma montagem "invisível" (BAZIN, 1991, p. 67) - desses artifícios e das relações entre imagens, construindo assim grandes continuidades espaço-temporais, que tentam nos fazer acreditar que estamos diante da realidade e não de uma construção.

Concluímos, portanto, algo muito importante para que possamos começar a conceber uma análise fílmica: o cinema - seja ele documentário ou não - não é realidade, nem sua cópia e não deve ser comparado com a mesma. 0 cinema é uma construção/montagem, que sendo mais ou menos "visível" (idem, ibidem), é

\footnotetext{
${ }^{3}$ De acordo com o próprio autor, o termo representação "envolve uma distinção entre a coisa e o objeto representado, uma não identificação, ainda que "no cinema a verossimilhança" seja " essencial para a construção de sentido"(MENEZES, 2003).
} 
responsável por dar sentidos às imagens, por meio da articulação de planos ${ }^{4}$, cenas e intervalos. Com isso, percorreremos o filme, nos atentando para essa montagem e consequentes sentidos que vão aos poucos construindo a história a ser contada.

O filme se inicia com uma gravação antiga, ainda em branco e preto, de um avião decolando. Neste mesmo plano, ouve-se uma música de suspense em fade $o u t^{5}$, à medida que o avião vai desaparecendo no céu. Merleau-Ponty (2008) afirma que "o vínculo entre som e imagem é muito estreito e esta última se transforma com a proximidade do som" (p. 112), e é por isso que ao vermos este plano, temos a sensação de que uma situação tensa se passava dentro ou ao redor daquele avião. 0 intervalo que liga este ao próximo plano é um movimento brusco de imagens seguido de alguns segundos de tela negra. 0 plano que se segue é muito sugestivo e nos traz uma boa ideia sobre o que e sob qual perspectiva o filme irá tratar a narrativa. É a sobreposição de duas imagens em preto e branco: a do planalto central e de uma explosão. Interpretando o planalto central como o polo de poder e a base do governo, a explosão indicaria algo que estaria ameaçando este governo. A cena seguinte dá um enquadramento bem próximo de partes dos jornais, acompanhadas de uma voz de um narrador ${ }^{6}$ (NiCHOLS, 2005) que narra partes de uma aparente notícia, que é simultaneamente grifada à medida que o narrador a lê. 0 fato de haver imagens mostrando que a mensagem lida pelo narrador advém do jornal Correio da Manhã traz legitimidade à fala do mesmo, uma vez que imprensa escrita era, paralelamente ao rádio, o principal meio de comunicação na época. Toda esta cena, que dura o tempo da mensagem lida pelo narrador, é uma mescla

\footnotetext{
4 "Plano" ou "tomada" é um registro sem cortes de um trecho do filme: o seu tempo varia. "Cena" ou "sequência" correspondem a um conjunto de tomadas/planos que formam um trecho contínuo da história o que está sendo contada. "Intervalos" são as passagens de um movimento para outro, justaposição de situações visuais que conduz a ação para o desdobramento cinético (AUMONT; MARIE, 2003).

5 "Fade out" é um recurso usado na montagem na qual o plano vai desaparecendo na tela até ela escurecer ou até mesmo quando a música vai diminuindo de volume até sumir por completo (AUMONT; MARIE, 2003).

${ }^{6} 0$ narrador aqui, apesar de aparecer algumas vezes, tenta ser evitado na maioria do tempo e não faz o papel de uma "voz de Deus" ou "voz over", nos termos de Nichols (2005), pois esta caraterística do cinema observativo - "se coloca acima da disputa; tem a capacidade de julgar ações no mundo histórico sem se envolver nelas". 0 narrador de Hércules se detém apenas a ler notícias de jornal da época, não fazendo julgamentos valorativos a respeito das cenas mostradas.
} 
de imagens em fusão ${ }^{7}$ de partes do jornal, das cidades, do povo nas ruas e do povo trabalhando.

As imagens do povo trabalhando e pelas ruas se casam muito bem com a mensagem narrada; e o segundo plano (planalto central e explosão) é completamente esclarecido com a frase "explosões de prédios que simbolizam a opressão". O sentido deste segundo plano pela mensagem transcrita forma o que Bazin (1991) chama de "montagem de atrações": "o reforço do sentido de uma imagem se dá pela aproximação de outra imagem, que não pertence necessariamente ao mesmo acontecimento" (p. 67). As partes dos jornais enquadradas pela câmera trazem as seguintes manchetes: "Embaixada procura Elbrick”, “O Manifesto”, "Reunião decide liberar o manifesto subversivo", "Raptores fazem exigências" e "Proposta dos sequestradores ao governo: embaixador por 15 prisioneiros", deixando claro que se que a suposta notícia se trata de um "Manifesto" de grupos armados de oposição ao governo, que sequestraram o embaixador americano em troca de 15 prisioneiros políticos. Vale aqui transcrever a mensagem transmitida pelo narrador, pois nos dará bases para compreender a escolha dessas imagens em fusão e nos apresentará o tema do documentário:

Ao povo brasileiro. Grupos revolucionários detiveram hoje o senhor Charles Burke Elbrick, embaixador dos Estados Unidos, levando-o para algum lugar do país, onde o mantém preso. Este ato não é um ato isolado, ele se soma a uma série de atos revolucionários já levados a cabo: assaltos a banco, dos quais se arrecadam fundos para a revolução, tomando de volta o que os banqueiros tomaram do povo e de seus empregados; ocupações de quartéis e delegacias, onde se conseguem armas e munições para a luta pela derrubada da ditadura; invasões de presídios, quando se libertam revolucionários para devolvê-los à luta do povo; explosões de prédios que simbolizam a opressão e o justiçamento de carrascos e torturadores.

A cena seguinte mostra imagens de um ambiente escuro, sendo que a iluminação está focada em direção a uma mesa. Nela se encontram bebidas e salgadinhos e, fundamentalmente, homens sentados ao seu redor, formando um conjunto que simula a atmosfera de um bar. A primeira parte da conversa apresentada ao espectador gira em torno de um debate acerca dos termos

\footnotetext{
7 “Fusão" é quando a imagem de uma cena ou uma sequência vai se dissolvendo enquanto a seguinte já está aparecendo; por alguns segundos, ou frações de segundos, estão na tela duas imagens diferentes (AUMONT; MARIE, 2003).
} 
designados para a ação realizada. Há uma espécie de consenso em relação ao emprego da palavra "sequestro" para a operação, pois ela tenderia a nos direcionar para o entendimento de uma ação criminosa. Uma das frases ditas na conversa deixa evidente esse debate, reproduzo-a: "a palavra é captura, porque a concepção da coisa é o seguinte: nós estamos capturando e trocando por prisioneiros, não é um sequestro. Sequestro é você assumir um crime e você não faz isso, está cometendo uma ação revolucionária". A frase também evidencia que o grupo mostrado não se trata dos "supostos prisioneiros", mas sim dos planejadores da operação.

A próxima cena é muito elucidativa para compreendermos o porquê do nome do filme. Ela nos traz a apresentação do nome do diretor, da produtora e por fim do filme, com um desenho gráfico ao fundo que imita uma carcaça de avião. A associação desse desenho com o primeiro plano do filme (a decolagem do avião) nos explicita, que "Hércules 56" se trata de um avião que, por todas as cenas vistas até esse momento, possivelmente está envolvido na operação sequestro do embaixador/ liberdade dos prisioneiros.

Até aqui já se possui os elementos suficientes para identificarmos a questão central do filme, bem como já podemos delinear os grupos constituintes. A questão do filme vai girar, portanto, em torno da reconstrução dessa operação enquadrada como um "ato terrorista", feita com base nos dois grupos constituintes do documentário, a saber, os planejadores e os presos políticos.

A cena que se segue é formada por consecutivos planos com imagens individuais de quatro dos libertados assistindo a imagens numa pequena tela segurada pelo diretor Silvio Da-Rin. Como percebemos, dado o caráter bilateral do acontecimento (de um lado havia os planejadores e, do outro, os libertos em decorrência das exigências dos primeiros), o documentário é organizado de maneira em que esses dois grupos de entrevistados são separados em ambientes distintos. Os planejadores simulam uma "aparente" conversa informal - pois, a todo instante a conversa é estimulada pelos filmmakers, nos termos de Ruby (1988) - sobre a operação, enquanto as entrevistas com os presos políticos, em contrapartida, são individuais e realizadas, ao que tudo indica, em seus respectivos lares. Essas entrevistas são estimuladas por fotos e cenas da época, que acabam 
contribuindo pouco para a reconstrução das histórias subjetivas, isto é, as histórias individuais dos agentes, e mais para a reconstrução da história (entendida como fato objetivo de uma construção temporal) do país. 0 último a ver as imagens nessa cena é José Dirceu anunciando o nome de Gregório Bezerra.

A partir deste momento, os presos políticos vão nos sendo apresentados, seguindo, sempre, uma montagem que varia pouco: uma fotografia individual de cada preso, passando pela alfândega mexicana, com uma legenda que, na parte superior traz o nome do indivíduo, e na inferior, a data de sua prisão e sua idade referente àquela data $\mathrm{e}$, posteriormente, o movimento ou partido ao qual pertencia. Essa apresentação precede trechos de entrevistas atuais dos entrevistados (caso ele esteja vivo), ou após sua soltura (caso esteja morto) ou ambas as situações. Na sequência de apresentações, o primeiro a ser apresentado foi, justamente, Gregório Bezerra. Após mostrar a sua fotografia, é mostrado um trecho de uma fala dele numa gravação mais antiga que contribui para o entendimento dos objetivos do documentário, reproduzo em parte a fala: "Se existe terrorismo, o terrorismo foi implantado pela ditadura militar em $1^{10}$ de abril de 1964. A consequência do terrorismo do governo gerou uma série de descontentamentos, principalmente no movimento estudantil...". Esse formato de montagem aparece repetidas vezes até os 27 minutos - quando Onofre Pinto, o últimos dos 15 presos, é apresentado -, intercalado com cenas históricas sobre acontecimentos introduzidos nas falas dos entrevistados e na conversa do bar. As cenas, compostas de fotos e vídeos dos diversos acontecimentos históricos, são mostradas com raros cortes e em seu áudio original, caracterizando traços de um documentário de "modo observacional". Mas esse efeito acaba sendo quebrado por causa das legendas que descrevem os acontecimento, os locais e as datas - característica, entre outras, de um documentário de modo expositivo. Da mesma forma que as cenas históricas com fotos e imagens vão sendo introduzidas à medida que os entrevistados vão citando os eventos, os personagens também o são, quando citados na fala de algum plano anterior. 
A apresentação dos "componentes da mesa da taverna", aquele que estamos chamando de grupo dos planejadores, acontece apenas aos 18 minutos de filme. A apresentação vai acontecendo à medida que os indivíduos vão se expressando durante a conversa entabulada, e assim, uma legenda traz seus respectivos nomes e filiação política. É interessante notar que os integrantes dentro de seus respectivos grupos não têm todos o mesmo status. Quer dizer, o eixo das reconstruções memorativas passa em especial por alguns membros principais dentro dos próprios. Esse é o caso do Franklin Martins em relação ao grupo dos "planejadores", e é o caso do Flávio Tavares para o grupo dos "presos políticos". Vale notar também que, essa forma de apresentação nos remete a um tema que se traduz muito claramente quando, ao longo da narrativa, as falas dos "planejadores" e dos "presos políticos" vão se contrapondo, vão tecendo as duas faces da narrativa: o tema da memória, sobre o qual trataremos mais adiante. É dessa forma bifacetada que a narrativa é construída, pincelando acontecimentos desde a implantação da ditadura, que vão se adensando nos acontecimentos nos meses que precederam e sucederam o sequestro/viagem dos presos, passando pelos caminhos percorridos pelos presos durante o exílio e concluindo com conclusões sobre o (des)sucesso da operação.

O grupo dos presos políticos, que até então se caracterizava por ser um grupo atomizado, com seus membros distribuídos espacialmente pelo país, não tinha uma unidade - assim como suas ideias. Todos os 15 membros desse grupo terão o seu ponto de contato na viagem rumo ao México. E o elo que os une ali é a situação de terror e violência (seja física, moral ou psicológica), tanto dos momentos passados dentro do avião, como também momentos anteriores a esse, incluindo a prisão, interrogações, afastamento da família e até mesmo tortura.

Essa parte começa mesmo com uma pequena montagem de imagens dando a introdução da Base Aérea do Galeão no Rio de Janeiro. Aqui há a confluência de montagem de imagens estáticas de fotografias e trechos de filmagens, sendo que existem muito fotógrafos no local, com melodia que cria uma espécie de expectativa que tende para uma tensão. A reconstrução daqueles momentos começa com Ibrahin contando a respeito da chegada e espera pelo embarque. A ele se segue os relatos de Flávio Tavares, que expõe o momento da foto dos 13 (pois os 
outros dois que faltavam estavam no Nordeste). À medida que Flávio vai contando, vai havendo uma demonstração figurativa, isto é, uma elucidação na própria imagem do que ele está contando. Isso cria, na própria foto que está sendo mostrada, uma sensação de temporalidade e não de um quadro estático. Há na própria fala de Flávio - quando trata do momento, as algemas são mostradas na foto, em demonstração de que eles são presos políticos - justamente a imagem que se quer passar a respeito da reconstrução da questão do filme. Isto é, como diz Flávio, eles são presos políticos, não são criminosos quaisquer. "...o preso político não é um culpado, não se sente um culpado, ele é uma vítima do sistema, do terror que ele, preso político, quer destruir".

A próxima cena é um retorno à narrativa do momento de transporte dos libertos que iriam rumo ao México. Flávio Tavares é o principal a reconstruir esses momentos dos acontecimentos. Com o intercâmbio de uma cena de decolagem, aludindo que o Hércules, depois de momentos de tensão contados por Flávio, finalmente decolara. Maria Augusta acaba contando também sobre o interior do avião, embora exista uma diferença perceptível do que é contado por Flávio e do que é contado por Maria Augusta. Não que exista divergências entre os relatos, o que há, na verdade, entre os dois, ou melhor dizendo, entre os relatos do Flávio e de quase todos os outros, é a objetividade da narração. Os outros acabam focandose sempre em recontar as sensações que sentiam no momento, os desconfortos próprios, enquanto Flávio, acaba mais por focar-se em descrever a cena, recontar uma história, mais afastadamente de suas próprias cargas emocionais.

Há também outro personagem que se destaca no interior do grupo dos presos políticos, o mais velho deles, Gregório Bezerra. Em torno dele existe uma construção de uma admiração e respeito que o torna, ao longo das falas, uma figura que se aproxima do heroísmo, às vezes uma figura mítica. Gregório tinha participado da rebelião comunista de 1935, ele era uma referência a essa juventude que estava naquele momento em furor revolucionário. Poder-se-ia fazer, assim, duas referências claras à essa admiração por Gregório ao longo das falas: a primeira delas está em uma das cenas do grupo dos planejadores, na qual eles expõem os motivos da escolha do nome de Gregório; a outra é a sequência de 
descrição da entrada do Gregório no Hércules, que se inicia com o relato de Maria Augusta e se finaliza com a descrição detalhada de Flávio Tavares.

Passa-se a várias discussões sobre as consequências daquela ação, tanto pelo grupo dos planejadores, quando por argumentações dos libertados. E aqui há um mar de opiniões distintas. As opiniões distintas ficam ainda mais marcadas na cisão do grupo dos libertados, que na verdade não era um grupo uniforme, era mais um amontoado de pessoas com visões de mundo até certo ponto similares, mas que não era o suficiente para se encaminharem conjuntamente em direção a uma causa comum. Fidel Castro faz um pedido para que todos fossem a Cuba num ato de apoio, e de lá cada um poderia ir para onde quisesse. Dessa maneira, há uma primeira divisão no grupo: fica no México Flávio Tavares, e vai para Paris Ricardo Vilas. Há em Cuba uma segunda cisão, basicamente entre aqueles que acreditavam na luta armada e os que não acreditavam.

Paralelamente a tudo isso, há para o grupo dos planejadores diversos debates de tópicos diferentes sobre o sequestro. Há a discussão sobre a relação estabelecida com o embaixador, os planos de fuga, a visão da liderança da operação, mas todas elas com um alto grau de consenso, tendo seu ponto de referência, como já foi dito anteriormente, em Franklin Martins.

O fim vai se encaminhando da mesma maneira que o filme se iniciou: com imagens das reações dos presos políticos ante as imagens que lhe foram mostradas, pelo diretor, por meio de uma pequena tela. Nesse momento, são reveladas ao espectador as imagens até então ocultas: os entrevistados assistem a imagens deles próprios desembarcando do Hércules 56. 0 filme termina com legendas que, curiosamente, vem ao final e não no início - o que facilitaria a compreensão da narrativa e dos grupos aqui estabelecidos. Os próximos planos, precedidos da legenda "Quinze presos políticos desembarcaram em liberdade do Hercules 56 da FAB na Cidade do México em 7 de setembro de 1959”, reafirmam para o espectador - que em meio à rápida montagem de cenas e planos não conseguiu identificar com clareza - os "personagens" e grupos apresentados ao longo de toda narrativa.

São (re)apresentados individualmente os (ex-)presos políticos por intermédio de uma foto correspondente à época da operação, que muda rapidamente por uma atual. Diferente das legendas iniciais de apresentação, nesta 
cena, elas trazem suas profissões, onde vivem, a data e a circunstância de sua morte (quando for o caso). E posteriormente seguem as seguintes legendas:

1o plano: Em setembro de 1969, Claudio Torres, Daniel Aarão Reis e Franklin Martins formavam a direção geral da Dissidência da Guanabara (DI-GB), organização revolucionaria que idealizou o sequestro do embaixador Charles Elbrick.

2o plano: Manoel Cyrillo e Paulo de Tarso Venceslau participaram da ação pela Ação nacional revolucionaria (ANL), juntamente com Virgilio Gomes da Silva (Jonas), comandante da operação, morto sob tortura em setembro de 1969, e Joaquim Câmara Ferreira (Toledo) morto sob tortura em outubro de 1970.

3o plano: Participaram da ação pela DI-GB/ MR-8 Antonio Freitas Filho, Cid Queiroz Benjamin, Claudio Torres, Fernando Gabeira, Franklin Martins, João Lopes Salgado, João Sebastião Rios de Moura, Sergio Rubens Araújo Torres e Vera Silvia Magalhães.

A estrutura das legendas reforça toda a estrutura do filme: os presos políticos são tratados individualmente, enquanto os planejadores do sequestro são considerados em bloco. As legendas descritas remontam o eixo central da narrativa, fechando o filme e formando a narrativa fílmica como um todo coeso. Citando Sorlin, “o cinema transmite representações e esquemas sociais, corta fragmentos do mundo exterior, que constitui em unidade contínuas, filmes que se impõem ao público" (1985, p. 190; tradução nossa), podemos dizer que esse todo coeso do qual falamos nada mais é do que a seleção de "pontos de vistas fotografáveis" (idem, ibidem) que acabam por revelar uma corrente de ideias específicas que o diretor deseja passar ao público.

Isso já é anunciado, como citamos, no segundo plano filme, quando há uma sobreposição da imagem do planalto central e de uma explosão. Em Hércules 56 fica claro que o diretor se ateve apenas aos relatos - e agora reorganizaremos esses grupos em "defensores" e os "opositores" da ditadura - dos opositores, sem ao menos citar qualquer informação ou mostrar qualquer imagem do grupo contrário. Identificar qual perspectiva da história o cineasta quer mostrar é um primeiro passo, mas compreender sua construção é algo que não trataremos neste estudo, mas pode ser refletido com base nas seguintes questões propostas por Sorlin (1985, p. 171): “Como os cineastas percebem o mundo exterior? E que imagem transmitem dele?". 
A última cena do documentário mostra imagens da mesa da taverna, com Franklin Martins fazendo o seguinte comentário, que é acompanhado de muitas risadas do restante do grupo:

[...] dois ou três dias antes do sequestro, eu recebo uma tribuna de debate, havia uma grande discussão política dentro da dissidência... aí eu recebo uma tribuna de debate de um companheiro, criticando o nosso imobilismo e falando das ações que outras organizações tinham feito. "E dizia assim: como diria Danton, precisamos de mais audácia, sempre audácia e ainda audácia!" Eu digo, esse cara não sabe de nada!

Seguem as legendas com a música "Aquele abraço" de Gilberto Gil. A música encerra o documentário de um modo bem descontraído, combinando muito bem com o comentário anterior e ainda citando o Rio de Janeiro, local onde aconteceu o sequestro.

\section{Modos de documentários: as tipologias de Bill Nichols}

De acordo com os estudos de Bill Nichols, podemos apontador para alguns "modos de documentários", que valem, aqui, serem tratados com mais cuidado. Descartaremos o uso da palavra gênero para caracterizar as categorias criadas por Nichols, na medida em que elas se aproximam muito mais daquela construção de tipos ideais presentes na sociologia weberiana.

0 esquema por nós construído tem, naturalmente, apenas como finalidade ser um meio de orientação ideal-típico [...] Tal construção torna possível, quando um fenômeno histórico se aproxima de uma dessas correlações em virtude de certas características ou do seu caráter global, determinar - por assim dizer - o respectivo lugar tipológico, apurando qual a sua proximidade ou distancia em relação ao tipo construído teoricamente. Nessa medida, a construção é, pois, meramente um recurso técnico para facilitar a exposição e a terminologia (WEBER, 2006, p. 18-19).

Ele cria, assim, algo como uma tipologia dos documentários. Essa aproximação com os tipos ideais se dá principalmente porque "a identificação de um filme com certo modo não precisa ser total" (NiCHOLS, 2005). Como os tipos ideais de Weber, Nichols utiliza certas características particulares que ele extrai da realidade e racionaliza-os ao limite, construindo, assim, tipos que funcionarão, em maior ou menor grau, para que a realidade empírica se aproxime dessas 
construções ideais. E ainda, tal pode ser o caso em que alguns trabalhos simplesmente não encontrem lugar nos tipos previamente construídos. E é nesse sentido que, tendo em vista os "modos de documentários" de Nichols, podemos dizer que Hércules 56 é eminentemente do modo "participativo".

Segundo os trabalhos de Nichols (2005), o modo participativo sofre algumas alterações que delineiam certos gradientes de variação dentro deste mesmo modo. Devido a alguns elementos específicos do cinema participativo, a saber, entrevistas com os participantes e interação com os eles, utilização de imagens de arquivos em uma tentativa de recuperar a história e foco em testemunhos, pode-se, assim, classificar Hércules 56 nessa modalidade fílmica, uma vez que, claramente, o documentário em questão faz uso dessas três técnicas comuns no cinema participativo.

Tanto nas cenas em que o grupo dos planejadores aparecem reunidos, quanto naquelas em que os presos políticos são entrevistados individualmente, podemos perceber a presença de câmeras e do próprio diretor em momentos de interação e participação com os entrevistados, estimulando situações "naturais" que estão sendo captadas pelas câmeras. Isso é o que ficou conhecido por cinéma vérité:

Como "cinema verdade", a ideia enfatiza que essa é a verdade de um encontro em vez da verdade absoluta ou manipulada. Vemos como o cineasta e as pessoas que representam seu tema negociam um relacionamento, como interagem, que formas de poder e controle entram em jogo e que níveis de revelação e relação nascem dessa forma específica de encontro. Se há uma verdade aí, é a verdade de uma forma de interação, que não existiria se não fosse pela câmera. Assim , ela é o oposto da premissa observativa, segundo a qual o que vemos é o que teríamos visto se estivéssemos lá no lugar da câmera (NiCHOLS, 2005, p. 155).

Assim, no cinema participativo, o que vemos na tela é o que podemos ver somente quando a câmera e o cineasta estão lá, participando da situação em nosso lugar. Todo o documentário em questão é construído dessa maneira: câmeras, produção e diretor participando da cena, colaborando para a construção da cena. Desse modo, Da-Rin acaba por, exitosamente, contrariar Erwing Goffman (2006), que diz que o espectador/audiência não deve ver os bastidores. A atuação do diretor, por vezes, é mais participativa e explícita e por outras, não tão enfatizada e 
aberta. Na cena da taverna, é possível ver Da-Rin interagindo e fazendo perguntas aos participantes para que aquela conversa se desenrole de maneira aparentemente natural, ao passo que nas cenas de testemunhos dos presos políticos isso fica menos evidente, pois é usada a técnica de entrevista, que, segundo Nichols, "representa umas das formas mais comuns de encontro entre cineasta e tema" (2005, p. 159) no modo participativo. "Os cineastas usam a entrevista para juntar relatos diferentes numa única história. A voz do cineasta emerge da tecedura das vozes participantes e do material que trazem para sustentar o que dizem" (idem, p. 160).

A outra característica típica desse modo, o resgate de imagens de arquivo muitas vezes imagens históricas - é garantida ao longo de várias cenas do filme, como o desembarque dos prisioneiros no México, a chegada do embaixador quando solto, a "passeata dos cem mil", o enterro de Edson Luiz, o embarque dos (ex-)presos políticos para Cuba e de ruas cubanas são bons exemplos de momentos nos quais Hércules 56 apresenta traços desse modo de documentário

E, talvez, o que seja a característica mais marcante de Hércules 56, a presença de vários testemunhos, nos leve de fato a concluir que tal documentário se encaixa na tipologia "participativo" de Nichols. Grande parte do documentário é montada com base em testemunhos dos presos políticos, estimulados por entrevistas "mascaradas".

Da mesma maneira que as histórias orais, que são gravadas e transcritas para servir como tipo de fonte primária. Com a qual essa forma se parece, mas da qual também difere na seleção e no arranjo cuidadoso do material de entrevista, a clareza e a franqueza emocional daqueles que falam dão aos filmes testemunhais uma característica convincente (NichOLS, 2005, p. 162).

Dessa maneira, nós como espectadores temos a impressão que estamos testemunhando uma situação de interação - que não deixa de ser negociada - entre cineasta e participante, carregada de emoções - bem como vemos em muitas das cenas em que alguns presos políticos chegam a derramar lágrimas ao fazer o seu relato ou a assistirem cenas históricas de arquivos, disponibilizadas pelo diretor no momento de interação. 
Assim, muitos dos documentários participativos, como Hércules 56, fazem uma compilação de entrevistas, testemunhos e de materiais de apoio, como imagens de arquivos, para construir a história que querem passar, de uma maneira que tem um amplo apelo convincente. Vale lembrar que, na verdade, esse modo de documentário, ao entrelaçar testemunhos, participação do diretor e imagens de arquivos, acaba por produzir "representações do mundo histórico provenientes de perspectivas específicas, tanto contingentes, quanto comprometidas" (idem, p. 62).

\section{Memória Coletiva e História: construções com base em Hércules 56}

O filme não só trata do tema da memória como é construído com base na composição de várias delas, o que acabou nos compelindo a fazer uma breve discussão acerca da teoria social da memória. Devido às escassas discussões sobre memória coletiva nas Ciências Sociais, principalmente em âmbito nacional, a maioria delas se pauta na teoria social da memória coletiva, parcialmente desenvolvida pelo sociólogo francês Maurice Halbwachs.

Cabe aqui dizer que a teoria de Halbwachs tem como seu ponto de partida a oposição cartesiana entre sujeito e objeto, de modo que na relação mantida entre os campos da subjetividade e da objetividade, há o deposito de uma primazia teórico explicativa no segundo, isto é, no campo da objetividade. Sendo assim, para essa teoria de inspiração claramente durkheimiana, há uma primazia com que os grupos, as coletividades, apresentam a sua relação ante os sujeitos, ante as individualidades. Em uma fundamentação argumentativa que pode ser apontada na direção seguinte: é possível dizer que os grupos colocam-se num plano de existência que é transcendente aos indivíduos (dotada, quiçá, de uma outra ontologia), indivíduos que são partes de grupos da mesma maneira que as células de um corpo compõe um corpo que as transcende imediatamente, mas que depende, também, da própria existência delas em sua composição. Com isso, tendo em vista uma noção de grupo que passa por essa direção brevemente delineada acima, poderíamos tratar de dois grupos "recordantes", os mesmos grupos sociais que imaginamos quando analisamos as técnicas de montagem, a saber, os planejadores do sequestro e os presos políticos. 
Os indivíduos do primeiro grupo - planejadores - recordam em uma situação coletiva que reforça a possibilidade da reconstrução da memória, uma vez que Halbwachs (2006) defende que, mesmo o indivíduo sozinho, recordaria por meio de memórias que não são apenas suas, pois indivíduos não lembram por si só, evocam a memória coletiva para recordarem de fatos, isto é, a memória que foi construída tendo como referência a interação entre os indivíduos. Interação presente na mesa e presente à época dos acontecimentos. Principalmente quando se trata , como vemos no filme, de depoimentos históricos, nos quais o passado é reconstruído da maneira mais favorável possível para o depoente, e diverso dos fatos que estão longe no tempo:

[...] a noção de que a representação do passado, que aparece aos nossos olhos como igual à matriz, trazendo a ilusão de que o passado está sendo literalmente reproduzido e encobrindo a diferença, pode ser utilizada e manipulada para atender interesses de grupos diversos (SEPÚLVEDA, 2003, p. 186).

A mesa, com a presença de todos os mentores do sequestro, estabelece quase uma situação de acareação dos fatos, na qual se torna muito mais difícil distorcer a realidade, como também previne eventuais lacunas de memória, já que elas passam a ser instantaneamente preenchidas pelo outro sujeito presente, ou como nas palavras de Halbwachs "se a nossa impressão pode se basear não apenas na nossa lembrança, mas também na de outros, nossa confiança na exatidão da informação será maior [...]" (HALBWACHS, 2006, p. 29).

0 grupo dos presos políticos, em contrapartida, estão em uma outra situação. A construção "individual” entre esses indivíduos e sua subsequente divergência seria sustentada, de acordo com a teoria de Halbwachs (2006), pela ideia de que se as recordações individuais são diferentes entre os indivíduos na medida em que cada um deles tem um trajeto de vida único, e que, ainda ao longo deste, adquire-se diferentes combinações do que ele chama de quadros sociais da memória ${ }^{8}$, que já estão constituídos. E é também por isso que o individuo teria uma visão perfilada, um ponto de vista da memória coletiva como um todo: "diríamos

\footnotetext{
${ }^{8} \mathrm{~A}$ teoria de Halbwachs nos ensina que a memória só pode ser pensada em termos de convenções sociais, as quais ele denomina como quadros sociais da memória, o que distancia os indivíduos de suas percepções e intenções individuais, isto é, de toda subjetividade. A relação entre os indivíduos e os quadros sociais foi compreendida como uma relação de estruturas sociais já dadas. Aqui, as escolhas e as memórias dos indivíduos são entendidas somente com base em quadros estáveis que o mundo lhe oferece.
} 
que cada memória individual é um ponto de vista sobre a memória coletiva, que este ponto de vista muda segundo o lugar que ali ocupo e esse mesmo lugar muda segundo as relações que mantenho com outros ambientes" (idem, p. 69).

No grupo dos planejadores, vemos uma memória coletiva mais homogênea que se unifica e se constrói ao longo da conversa. No grupo dos presos políticos, por outro lado, a memória coletiva é mais fragmentada, com algumas partes dos relatos sendo convergentes. Diferentemente dos primeiros, os segundos não estão em uma situação de acareação, mas sim rememorando isoladamente em frente à câmera. Isso é possível, na medida em que "para [se] confirmar ou recordar uma lembrança, não são necessárias testemunhas no sentido literal da palavra, ou seja, indivíduos presentes sob uma forma material e sensível" (idem, p. 31). Embora a essência das memórias relatadas seja a mesma - dado que elas partem de uma objetividade que independe do sujeito -, a memória do grupo dos presos, como um todo, ainda nos parece muito mais fragmentada se comparada aos planejadores, pois ali as diferentes posições desses indivíduos, dentro de seu respectivo grupo, ficam muito mais marcadas, o que acaba se refletindo no relato de memória que estão realizando. Além disso, neste grupo, as lacunas de memórias são mais explícitas por dois motivos: elas não são imediatamente cobertas por outros integrantes, reforçando assim a exatidão da informação e também, esses indivíduos, peculiarmente, como é notado ao longo de suas falas, estão rememorando, sobretudo, eventos traumáticos. "Aqueles que sofrem o trauma", diz Sepúlveda, "ficam presos no interior do evento", na medida em que, nos momentos dos choques traumáticos, os indivíduos gravam na memória o evento puro, como acontecera, sem ter tido a possibilidade de perceber, interpretar e responder ao estímulo dos agressores (SEPÚLVEDA, 2003). Eventos traumáticos, portanto, deixam não apenas marcas em "estado puro" nos indivíduos que participaram do evento, como também em gerações subsequentes para as quais são transmitidas ou até mesmo omitidas essas lembranças.

Dado o caráter histórico de Hércules 56 e tendo em vista sua publicação nacional, é possível dizer também que o presente documentário acabou se prestando como colaborador na tentativa de lançar bases para a edificação de parte da memória coletiva nacional acerca do episódio relatado, pertencente a um 
excepcional período da história brasileira, que deve ser lembrado pela nação. Ademais, o cinema recria a história pelo prisma da linguagem fílmica, sendo capaz de intervir na história com filmes e documentários, que sob a aparência da representação, edificam o contexto histórico. A oportuna citação de Nichols (2005, p. 152) sobre o documentário $O$ triunfo da vontade, aplica-se, em menor escala, também ao que estamos construindo para Hércules 56: "demonstra o poder da imagem na representação do mundo histórico, no mesmo momento em que participa da construção do próprio mundo histórico". Hércules 56: fator e produto da memória coletiva nacional.

\section{Referências}

Aumont, J.; Marie, M. (2003). Dicionário teórico e crítico de cinema. Campinas, Ed. Papirus.

BAZIN, A. (1991). "A evolução da linguagem cinematográfica". In: O cinema: ensaios. São Paulo, Ed. Brasiliense.

Benjamin, W. (1985). Magia e técnica, arte e política: ensaios sobre a literatura e história da cultura .São Paulo, Ed. Brasiliense.

BordWEll, D. (1993). The Cinema of Eisenstein. Cambridge, Harvard University Press.

FouCAULT, M. (2001). "O que é um autor". In.: Ditos e Escritos III. São Paulo, Ed. Forense.

Goffman, E. (2006). A representação do eu na vida cotidiana. Petrópolis, Editora Vozes.

HalbWachS, M. (2006). A memória coletiva. São Paulo, Ed. Centauro.

HUSSERL, E. (2006). Lições para uma fenomenologia da consciência interna do tempo. Trad. de Pedro M. S. Alves. Lisboa, Imprensa Nacional Casa da Moeda.

MEnEzes, P. (2003). "Representificação: as relações (im)possíveis entre cinema documental e conhecimento". Revista Brasileira de Ciências Sociais, vol. 18, n. 51, fev.

(2007). "Les Maîtres Fous, De Jean Rouch. Questões Epistemológicas da relação entre cinema documental e produção de conhecimento". Revista Brasileira de Ciências Sociais, vol. 22, n. 63, p. 81-91, fev.

Merleau-Ponty, M. (2008). “O cinema e a nova psicologia”. In: Xavier, I. (org.). $A$ experiência do cinema. São Paulo, Ed. Graal. 
Nichols, B. (2005). Introdução ao documentário. São Paulo, Ed. Papirus.

RuBY, J. (1988). “The Image Mirrored: Reflexivity and the Documentary Film”. In: New Challenge for Documentary. Manchester, Manchester Press.

SEPÚlvedA, M. (2003). Memória coletiva e teoria social. São Paulo, Ed. Annablume.

SoRLIN, P. (1985). Sociologia del Cinema. Paris, Ed. Aubier.

VERTOV, D. (1983). Variação do manifesto, resolução do conselho dos três e extrato do $A B C$ dos Kinoks. In: XAVIER, I. (org.). A experiência do cinema. São Paulo, Ed. Graal.

WEBER, M. (2006). “Consideração intermediária”. In: Sociologia das religiões e consideração intermediária. São Paulo, Ed. Relógio D'agua.

Recebido em janeiro/2011

Aprovado em maio/2011 